\title{
Inefficiencies in regional commuting policy
}

\author{
Toon Vandyck* Stef Proost*
}

August 17, 2011

\begin{abstract}
This paper discusses investments in transport infrastructure and incentives for commuting taxes in a multiregional setting. We study the horizontal and vertical interactions between governments. We identify incentives for strategic and tax exporting behavior that might lead to underinvestment in transport infrastructure. Furthermore, we show that the intensity of the strategic behavior is affected by geographic firm ownership structure, the number of labor-supplying regions and the revenue-sharing mechanism in the federation. A numerical example applies the insights on commuting in Belgium.
\end{abstract}

Keywords: Regional tax competition, commuting subsidies, transport pricing, regional labor markets

JEL classification: H73, H77, J61, R23, R48, R53.

${ }^{*}$ CES, KuLeuven. We thank the participants of the 2011 ERSA Summer School for helpful comments. Financial support of the IWT-SBO Flemosi and the SUSTAINCITY - FP7 projects is gratefully acknowledged. 


\section{Contents}

1 Introduction $\quad 4$

2 The model $\quad 6$

3 Federal government in control $\quad 10$

3.1 Social optimum . . . . . . . . . . . . . . . . . . . 10

3.2 Attaining first best under free movement of workers . . . . . . . . . . . . 11

4 Strategic behavior of regional government $\quad 13$

4.1 Regional transport investment . . . . . . . . . . . . . . . . 13

4.2 Regional transport investment and commuting subsidy when labor is taxed . $\quad 15$

4.2.1 Lump sum taxation and only commuting subsidies . . . . . . . . . . . 16

4.2.2 Labor taxation and commuting subsidies . . . . . . . . . . . . 17

4.2.3 Labor taxation, transport investments and commuting subsidies . . . 17

5 Strategic behavior of city government $\quad 18$

5.1 Transport investments and commuting taxes at city level . . . . . . . . . 18

6 Nash competition in transport investments 20

7 Alternative scenarios $\quad 21$

7.1 Three regions . . . . . . . . . . . . . . . . . . . . 21

7.2 Revenue sharing mechanisms . . . . . . . . . . . . . . . 21

7.3 Ownership structure or profit taxes . . . . . . . . . . . . 23

8 Numerical example for Belgium $\quad 24$

9 Conclusions $\quad 27$

$\begin{array}{lr}\text { Appendix } & 30\end{array}$

$\begin{array}{ll}\text { A Regional transport investments } & 30\end{array}$

B Trade-off $\quad 30$

C Nash competition in investments $\quad 31$

$\begin{array}{ll}\text { D } \text { Three regions } & 32\end{array}$ 


\section{List of Figures}

1 Model representation with constantly decreasing marginal productivities. . . 9

2 Welfare effects of a restricted number of commuters. . . . . . . . . . . 15

\section{List of Tables}

1 Model variables . . . . . . . . . . . . . . . . . . . . 9

2 Welfare effects of limiting the number of commuters . . . . . . . . . . 15

3 Data used for calibration . . . . . . . . . . . . . . . . . . 24

4 Flanders sets number of commuters* . . . . . . . . . . . . . 26

5 Brussels sets commuting tax ${ }^{*} \ldots \ldots \ldots \ldots$ 


\section{Introduction}

Commuting is a pervasive phenomenon in urbanized areas nowadays. Many people travel to work by car or by means of public transport. Agglomeration forces result in a higher concentration of economic activity. Together with residential structures, these spatial patterns create employment centers that attract workers from surrounding cities, regions or countries. In Belgium, for instance, the capital Brussels attracts nearly 600000 commuters on a daily basis from surrounding regions Flanders and Wallonia. Moreover, numerous countries stimulate commuting by providing some sort of commuting subsidy, for instance by making commuting costs income tax deductible or by heavily subsidizing public transport. In many countries, political decisions on transportation issues are made by different levels of government. For instance, a city can decide on parking fees and tolls, the regional authorities on investments in roads and the federal government holds responsibility for rail transport. This paper discusses some aspects of transport policy in a federal state.

The relevant literature forms an overlap between two areas in economics. On the one hand, the model that will be presented here draws upon urban economics literature, in which spatial aspects, such as the location of firms and residents, are crucial. Related central features are agglomeration, congestion and environmental externalities. The reasons for a commuting subsidy or a road toll usually build upon externalities, market imperfections and pre-existing distortions. Optimal taxation has received quite some attention in this field. Mirrlees (1972) discusses the role of commuting subsidies in the presence of environmental externalities in the city. The trade-off between congestion and agglomeration effects that an optimal road toll faces is considered by Arnott (2007). He models labor-leisure choice explicitly, and individuals decide on the proportion of days to work. Graham and Van Dender (2008) and Verhoef and Nijkamp (2003) discuss similar tradeoffs.

While road pricing can serve to internalize environmental and congestion externalities, transport taxes can also have a negative effect on labor supply ${ }^{1}$ or labor force participation (Parry and Bento 2001). Commuting subsidies may partially offset these distortions. In addition, they can be introduced to stimulate agglomeration externalities. Welfare effects of the seemingly contradictory road tolling and commuting subsidies may therefore be superadditive in a spatial framework (Verhoef and Nijkamp 2003). These considerations result in some literature in urban economics pointing out the inefficiencies and creation of urban sprawl induced by subsidizing transport (Brueckner 2005), while others illustrate that commuting subsidies may improve welfare in a second-best framework (Wrede 2001, Wrede 2009). Wrede

\footnotetext{
${ }^{1}$ Gutierrez-i-Puigarnau and van Ommeren (2010), however, claim in an empirical paper that "changes in labour supply are likely not fundamental to the discussion to what extent these policies [that affect commuting] affect welfare".
} 
(2009) shows that commuting subsidies that countervail a distortive wage tax are efficiency enhancing if and only if labor supply is shifted from a less to a more productive area. Borck and Wrede (2009) give a similar rationale for commuting subsidies. They present a model in which workers, choosing place of residence and place of work simultaneously, generate urbanization externalities in production. If agglomeration rents are captured locally, commuters do not get their share of these rents. In this setting, commuting subsidies may lead to a first-best solution.

On the other hand, the important insights in tax competition can be found in the literature on fiscal federalism, where different government levels or regions affect each other's budget by choosing taxes and expenditures. An overview of the literature on tax competition in the transport sector is presented by De Borger and Proost (2004).

Typically, a distinction is made between horizontal and vertical tax competition. Horizontal tax competition occurs between governments at the same level. Several regions, states or länder in a federal country having the responsibility over a range of instruments could be an example to bear in mind along the discussion. Tax competition occurs when different regions compete for a mobile tax base, e.g. mobile capital or labor. Taxes set by one region then affect tax revenues of the other regions. For instance, a region can set lower taxes on capital to attract firms. Another tax externality is tax exporting, which describes the attempt to shift taxes to non-residents. The fact that a region does not take the effects on other regions into account when deciding on its tax schedule can introduce allocative distortions and may result in overall efficiency losses (Oates 1999). The same holds when congestion, environmental or agglomeration externalities are not fully accounted for. However, some conditions have been set out under which tax competition could display efficiency enhancing features (see De Borger and Proost (2004) for a discussion). De Borger, Dunkerley and Proost (2007) discuss a model with horizontal tax and transport capacity competition to show tax exporting and underinvestment in transport infrastructure by the regions. De Borger et al. (2005) study tax competition between countries in a network with parallel links. A distinction is made between local and transit traffic. The results suggest that cooperative setting of road tolls leads to only small welfare gains compared to non-cooperative transit tolling.

Vertical fiscal externalities describe the interaction between higher and lower level governments' tax policies and revenues. For instance in case of a shared tax base, the local government might set taxes too high because the impact on federal government tax revenue is ignored. The federal government could try to counterbalance the resulting inefficiencies with a set of taxes, subsidies and grants. Proost and Sen (2006) present a model in which several government levels control different transport pricing instruments. The potential efficiency losses, estimated by comparing the case with multiple government levels to the social 
optimum, show limited detrimental welfare effects. Ubbels and Verhoef (2008) study vertical competition between the region and city. Governments compete in road pricing and capacity (as in De Borger, Dunkerley and Proost (2007) in a horizontal competition setting), which may result in a strong tendency of tax exporting and possibly harmful effects for overall welfare.

This paper develops a small model covering two or more regions with heterogeneous productivities. The set-up is closely related to the one developed by Borck \& Wrede (2009) and Venables (2007), with the difference that residence choice is kept fixed. The new element in this paper is that it incorporates regional transport policies, which creates incentives for subnational governments to behave strategically when deciding on optimal commuting subsidies and transport investments. The impact of these decisions is explored in a simple general equilibrium framework, thus incorporating productivity effects of labor allocation (i.e. commuting) decisions (thereby differing from Proost and Sen (2006); De Borger, Dunkerley, \& Proost (2007); and Ubbels \& Verhoef (2008)). The next section introduces the model and the underlying assumptions. Section 3 derives the first best allocation of workers and the optimal investments in transport. Subsequently, in sections 4 and 5, we analyze decisions on transport policy made at the regional and city level respectively. Section 6 introduces Nash competition between city and regional government with transport investments as a strategic variable, whereas section 7 questions what the impact is of modifying some assumptions. Before summarizing the findings in the conclusion, a numerical example illustrates the model for two Belgian regions.

\section{The model}

The economic model has three main actors. First, individuals choose labor location, i.e. whether to commute or not. For the sake of simplicity, place of residence is kept fixed. Second, firms demand labor in a perfectly competitive environment. Third, a (multi-level) government influences commuting flows via its commuting policy. Initially, a model with only two regions is considered. This simplifies the analysis and yet captures some basic intuitions. In many realistic situations, the structure of commuting flows can be reduced to include only a limited number of areas, especially when labor mobility is limited. We return to this assumption in section 7 .

Now consider individuals. Let $N_{1}$ denote the number of homogeneous individuals that live and work in region 1 ( $N_{2}$ for region 2$)$. The number of people that reside in region 1 and work in region 2 , i.e. the commuters, is labeled $N_{12}$. So, three types of individuals can be 
distinguished: $i=1$ for inhabitants of region 1 that work in their region of residence; $i=2$ for people working and living in region 2 ; and $i=12$ for residents of region 1 who commute to region 2 .

Region 2 attracts commuters because of its higher productivity and wages. This set-up can be regarded as region 2 being an urban area or a city, surrounded by a rural area or the periphery, region 1. Equivalently, region 2 is the central business district (CBD) to which a daily commuting flow is observed. The fixed total number of residents in region 1 equals $N=N_{1}+N_{12}$.

The number of individuals is sufficiently large, such that any individual takes prices and wages as given. The economy is closed and there is no migration into the economy, such that the total number of individuals is fixed. Labor supply is perfectly inelastic, so everybody works full-time. An individual of region 1 has the choice to work in his region of residence or to commute to the other region. No distinction is made between transport modes and leisure trips are ignored. If a worker decides to commute, he faces a fixed commuting cost c. This can include both time and monetary $\operatorname{costs}^{2}$. In the remainder of the paper, the commuting costs are thought of as using up physical resources. Note that by assuming that the commuting cost $c$ is independent of the number of commuters, congestion externalities are not incorporated. Governments can invest in transport infrastructure, in order to reduce the commuting costs. We will denote the level of these infrastructure investments with $\psi$ for the federal or regional level, and with $\phi$ for investments in transport in the city (region 2). The costs associated with these investments are described by a cost function $K(\psi)$ for the federal or regional government - we assume they dispose of the same investment technology - and by the function $K_{c}(\phi)$ for the city government.

Furthermore, assume an individual's utility $U_{i}\left(x_{i}\right)$ depends only on the consumption of a homogeneous good $x_{i}$. This means there are no substitution possibilities on the consumption side. Freight costs are ignored and as the good is homogeneous and there are many producers, the price of the homogeneous good can be normalized to 1 in both regions. Consumers cannot distinguish between goods produced in different regions. One of the implications is that consumers cannot opt to consume the product that is produced locally, which could be interesting e.g. if the agent holds a profit share in local firms.

Next, consider the production side of the economy. Firms use homogeneous labor as the only input. This implies there is no opportunity to substitute on the production side, firms are not concerned with their optimal input mix and the stock of capital is fixed. A higher stock of capital in the urban area could then account for the higher productivity in this region.

\footnotetext{
${ }^{2}$ In fact, any disutility of commuting can be included in this commuting cost. Stutzer and Frey (2008), for instance, report a lower subjective well-being of commuters.
} 
In addition, a firm pays its workers a uniform wage equal to their marginal product and a distinction between low- and high-skilled workers is absent. This may be a useful distinction, however, since a city's labor demand might consist of a high share of skilled workers. The allocation of skilled and unskilled workers across regions is therefore not discussed in this paper. An analysis of commuting policy in a setting with heterogeneous workers, including redistributive impact of commuting subsidies, can be found in Borck and Wrede (2008).

Furthermore, firms produce a single homogeneous consumption good. This rules out product differentiation. All goods are of equal quality and regions cannot specialize in producing a specific good. Introducing product heterogeneity and firm specialization would complicate the analysis significantly.

Different technologies are at firms' disposal in the different regions: $F_{1}\left(N_{1}\right)$ represents the production function in region 1 and $F_{2}\left(N_{12}+N_{2}\right)$ reflects the technology in region 2 . We assume that region 2 is the more productive one, resulting in higher wages in region 2. This is the reason why only commuting in one direction is discussed. The higher productivity could be caused by some natural advantage or by agglomeration economies. There is extensive evidence on the nature and sources of agglomeration economies, as discussed by Rosenthal and Strange (2004). They claim that labor market pooling, input sharing and knowledge spillovers - the sources already suggested by Marshall (1920) - are important factors in explaining higher productivities in cities. In this paper, however, firms will not move towards more productive regions, as firm location is assumed to be fixed. Mobility is focused on workers, whereas firms' location decisions are not part of the discussion here. Firms face decreasing returns to scale in both regions. Profits are assumed to be paid out to regional shareholders, so they are a benefit to the region in which the firm is located. Only section 7.3 deviates from this assumption and discusses cross-border firm ownership. Later in the paper, specific functional forms for the production functions in both regions will be used to illustrate and clarify the impact of the commuting flow on profits and wages. Linearly decreasing marginal products offer a simple, albeit restrictive framework to discuss the model implications. The major drawback of this modeling approach is the absence of endogenous agglomeration externalities, that point to marginal productivities that increase with the number of workers.

Figure 1 gives a graphical summary in a situation with constantly decreasing marginal productivities in both regions, whereas table 1 summarizes the main variables used in rest of the paper. 


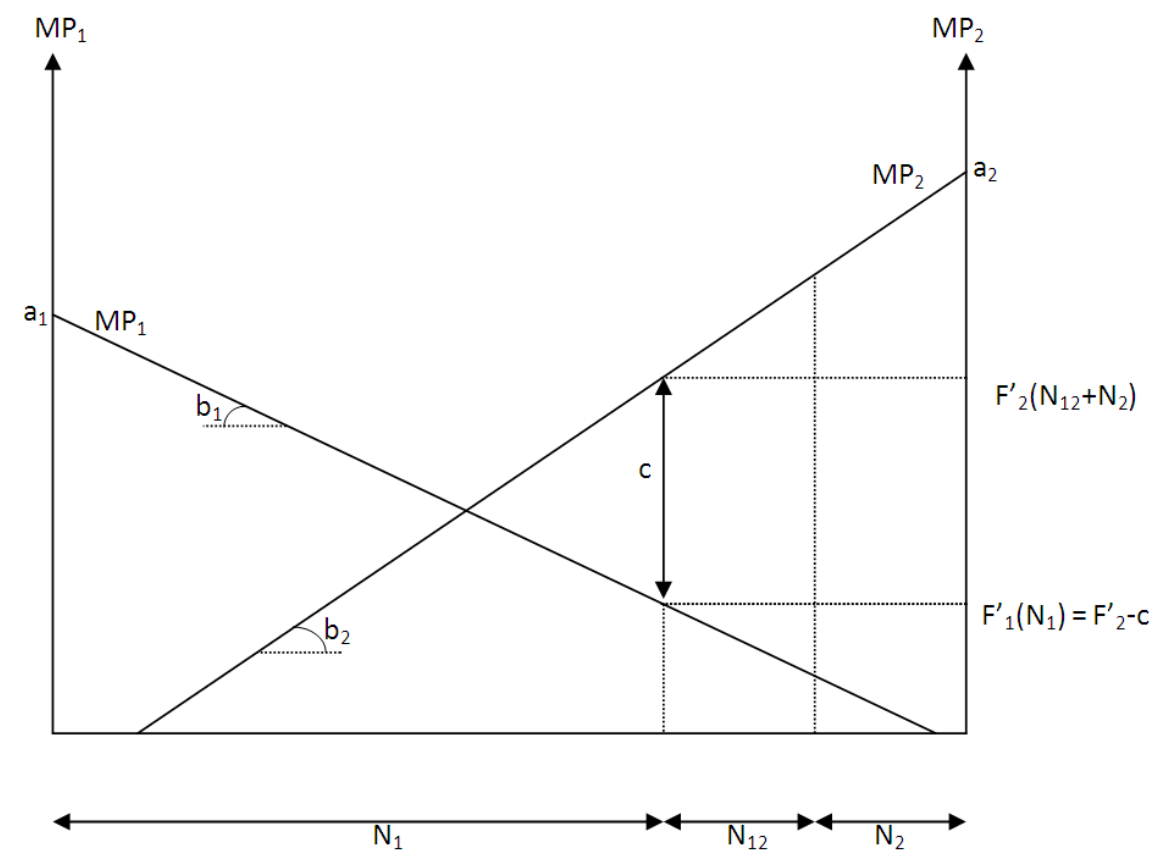

Figure 1: Model representation with constantly decreasing marginal productivities.

\begin{tabular}{c|c}
\hline \hline Variable & Explanation \\
\hline$i$ & Region $i=1,2$ \\
$N$ & Total number of people living in region 1 \\
$N_{i}$ & Number of people working and living in region $i$ \\
$N_{12}$ & Number of commuters from region 1 to region 2 \\
$c$ & Commuting cost \\
$F_{i}$ & Production in region $i$ \\
$F_{i}^{\prime}$ & Marginal product in region $i$ \\
$\psi, \phi$ & Investments in transport infrastructure \\
$K_{(c)}$ & Transport infrastructure investment cost (in region 2, the city) \\
$\pi_{i}$ & Profits in region $i$ \\
$t$ & Labor tax rate \\
$s$ & Commuting costs subsidy rate \\
$W_{(i)}$ & (Regional) welfare \\
\hline \hline
\end{tabular}

Table 1: Model variables 


\section{$3 \quad$ Federal government in control}

Before we move to regionalized policies, we discuss the efficient outcome for the federation as a whole. The results obtained here will serve as a benchmark. First, we assume that the government can simply choose the number of commuters. Next, we investigate optimal transport policy decisions when individuals are free to choose their job location.

\subsection{Social optimum}

This section derives the labor allocation and investment in transport infrastructure in a first best framework. The welfare maximizing social planner can decide on the optimal allocation of workers over the two regions and the level of transport investments. Since the utility of individuals only depends on consumption, the social planner maximizes the total production, which comprises profits and incomes, and takes commuting and infrastructure investment costs into account:

$$
\underset{N_{12}, \psi}{\operatorname{Max}} W=F_{1}+F_{2}-(c-\psi) N_{12}-K
$$

The first order conditions with respect to the number of commuters $N_{12}$ and the level of investment $\psi$ display a clear intuition:

$$
\begin{aligned}
F_{1}^{\prime} & =F_{2}^{\prime}-(c-\psi) \\
N_{12} & =\frac{\partial K}{\partial \psi}
\end{aligned}
$$

Condition (2) states that an efficient labor allocation implies that the gap between marginal products in both regions equals the commuting cost (which can be decreasing through investment). Expression (3) simply states that the marginal benefit of lowering transport costs should equal marginal costs of investing. If one assumes linearly decreasing marginal products in both regions,

$$
\begin{aligned}
& F_{1}^{\prime}=a_{1}-b_{1} N_{1} \\
& F_{2}^{\prime}=a_{2}-b_{2}\left(N_{2}+N_{12}\right),
\end{aligned}
$$

$a_{1}, a_{2}, b_{1}, b_{2}>0$, and increasing marginal cost of infrastructure investment

$$
K(\psi)=k \psi+\frac{1}{2} l \psi^{2}
$$


with $k, l>0$, we obtain an explicit expression for the optimal number of commuters. The first order conditions become

$$
\begin{aligned}
& N_{12}=\frac{1}{b_{1}+b_{2}}\left(a_{2}-a_{1}-c+\psi+N b_{1}-N_{2} b_{2}\right) \\
& N_{12}=k+l \psi
\end{aligned}
$$

From expression (7) we see that the optimal number of commuters is increasing in the difference of marginal products and decreasing in transport costs. The number of commuters increases with transport investments. Solving this system of equations, we find explicit expressions for the optimal number of commuters and for the optimal transport investment level:

$$
\begin{aligned}
N_{12}^{*} & =\frac{l}{l\left(b_{1}+b_{2}\right)-1}\left(a_{2}-a_{1}-c+N b_{1}-N_{2} b_{2}-\frac{k}{l}\right) \\
\psi^{*} & =\frac{1}{l\left(b_{1}+b_{2}\right)-1}\left(a_{2}-a_{1}-c+N b_{1}-N_{2} b_{2}-k\left(b_{1}+b_{2}\right)\right)
\end{aligned}
$$

Unsurprisingly, this last expression shows that the optimal investment level will be higher if the cost parameters $k$ and $l$ are lower. We make two important assumptions. First, we assume that the optimal number of commuters is positive, even without transport investments: $a_{2}-$ $a_{1}-c+N b_{1}-N_{2} b_{2}>0$. Secondly, the parameters of the investment cost function are such that $\psi^{*}$ is positive. The functional forms (4), (5) and (6) will be used throughout the paper.

\subsection{Attaining first best under free movement of workers}

Instead of the social planner deciding directly on the number of commuters, we now let indiviuals choose their location of work. Assume there is an exogenous labor tax $t$. Furthermore, there is a perfectly competitive labor market, such that workers are paid there marginal product. In this section, the government does not allocate workers to regions, but individuals decide where to work. Place of residence is assumed to be exogenous and fixed. We then have a new equilibrium condition (the investment condition, (3), does not change):

$$
(1-t) F_{1}^{\prime}=(1-t) F_{2}^{\prime}-(1-s)(c-\psi)
$$

Expression (11) defines the spatial equilibrium and states that commuting will equalize net wages. $s$ represents the fraction of commuting costs that is subsidized. So, an individual that crosses jurisdictional borders to work, will be compensated through a higher wage. We ignore compensation in the form of lower housing prices, since the assumption of fixed 
residence location cancels out land rent aspects. Van Ommeren and Rietveld (2007), for instance, obtain only partial (how much depends on the wage bargaining power between worker and employer) compensation for commuting costs through wages in a setting with imperfections in housing and labour markets. Rewriting the spatial equilibrium condition (11) gives

$$
F_{1}^{\prime}=F_{2}^{\prime}-\frac{1-s}{1-t}(c-\psi)
$$

This shows that the combination of commuting costs and labor taxation distorts labor location decisions. The federal government can make commuting expenses tax deductible, i.e. $s=t$, to correct the distortion in the labor market. This allows to achieve the efficient, first best outcome. Expression (12) then simply reduces to equation (2), such that an efficient spatial distribution of labor is guaranteed. Decisions on infrastructure investments remain unchanged. Non-distortionary lump sum taxes instead of labor taxation would result in an optimal commuting subsidy of $s=0$. In conclusion, the federal government's incentives for making commuting expenses tax deductible are derived from correcting the pre-existing distortion induced by the combination of labor taxes and commuting costs. 


\section{Strategic behavior of regional government}

We now shift the responsibility of transport decisions to the government of the peripheral region. First we discuss strategic incentives in transportation policy in depth. Afterwards, we include a second policy instrument and amplify the analysis to include labor tax distortions.

\subsection{Regional transport investment}

This section analyzes in detail, in a simplified setting, whether the regional government has incentives for strategic behavior that would lead to over- or underinvestment in infrastructure. In order to do so, we regionalize the decisions on transport infrastructure investment $\psi$ and assume that the federal government continues to make commuting costs tax deductible, $s=t$. We abandon the latter assumption in the next section. The full deductibility of commuting expenses cancels out the labor tax distortion. We also assume here that the region does not have the opportunity to influence commuting flows through commuting subsidies. For the sake of clarity, we include all arguments in the notation in this section. The objective function of the government of region 1, when maximizing welfare of its residents, takes local profits, incomes of its residents and investment costs into account:

$$
\underset{\psi}{\operatorname{Max}} W_{1}(\psi)=\underbrace{\pi_{1}\left(N_{12}(\psi)\right)}_{\text {Profits }}+\underbrace{N_{1}(\psi) \frac{\partial F_{1}\left(N_{12}(\psi)\right)}{\partial N_{12}(\psi)}+N_{12}(\psi)\left(\frac{\partial F_{2}\left(N_{12}(\psi)\right)}{\partial N_{12}(\psi)}-c+\psi\right)}_{\text {Real incomes }}-\underbrace{K(\psi)}_{\text {Inv. cost }}
$$

Note that this objective function does not include regional government revenue and thus assumes a "juste retour" distribution of federal tax revenue, i.e. every region receives exactly the amount of taxes paid by its residents. Therefore tax revenue is not included in the objective function, since this is just a transfer from a region's residents to its government ${ }^{3}$. The first order condition becomes:

$$
\underbrace{\frac{\partial N_{12}(\psi)}{\partial \psi}\left[\frac{\partial \pi_{1}\left(N_{12}(\psi)\right)}{\partial N_{12}(\psi)}+N_{1}(\psi) \frac{\partial^{2} F_{1}\left(N_{12}(\psi)\right)}{\partial N_{12}(\psi)^{2}}+N_{12}(\psi) \frac{\partial^{2} F_{2}\left(N_{12}(\psi)\right)}{\partial N_{12}(\psi)^{2}}\right.}_{\text {Strategic effect }}]+N_{12}(\psi)=\frac{\partial K(\psi)}{\partial \psi}
$$

If region 1, the peripheral region, perceives its position on the labor market in region 2, the city, as dominant, a strategic effect appears. To see where the strategic concerns

\footnotetext{
${ }^{3}$ Similarly, we could have assumed that the regional government levies lump sum taxes to finance its investments. The two assumptions only differ in government budget constraints.
} 
of the regional government stem from, one can disentangle the strategic effect into three components. Firstly, the number of commuters has an impact on profits in region 1. This is reflected by the term $\frac{\partial \pi_{1}\left(N_{12}(\psi)\right)}{\partial N_{12}(\psi)}$. Secondly, there will be an effect on wages in region 1 , which is captured by $\frac{\partial^{2} F_{1}\left(N_{12}(\psi)\right)}{\partial N_{12}(\psi)^{2}}$. Thirdly, the city wages will be affected by the number of commuters. These wages are relevant for the regional government since they are also paid out to individuals that reside in region 1 but work in the city. This effect shows up in $\frac{\partial^{2} F_{2}\left(N_{12}(\psi)\right)}{\partial N_{12}(\psi)^{2}}$.

If one assumes linearly decreasing marginal products in both regions, as in (4) and (5), the first two components cancel each other out, which implies a redistribution of income between workers and firm-owners in region 1 . The first order condition (14) then becomes

$$
N_{12}(\psi) \underbrace{\left(1-\frac{b_{2}}{b_{1}+b_{2}}\right)}_{<1}=\frac{\partial K(\psi)}{\partial \psi} .
$$

This shows that the investment level will now be lower than in the social optimum ${ }^{4}$. The marginal benefits of investing, on the left-hand side of (15), are reduced. Due to the strategic effect, region 1 will invest less in transport infrastructure. This will restrict the number of commuters but will increase their wage. As a result, the investment cost $K(\psi)$ will also be lower. The decreased commuting flow is welfare-reducing for region 2 and for the federation as a whole. The distinct effects are shown in detail in figure 2 and table 2.

\footnotetext{
${ }^{4}$ See appendix A.
} 


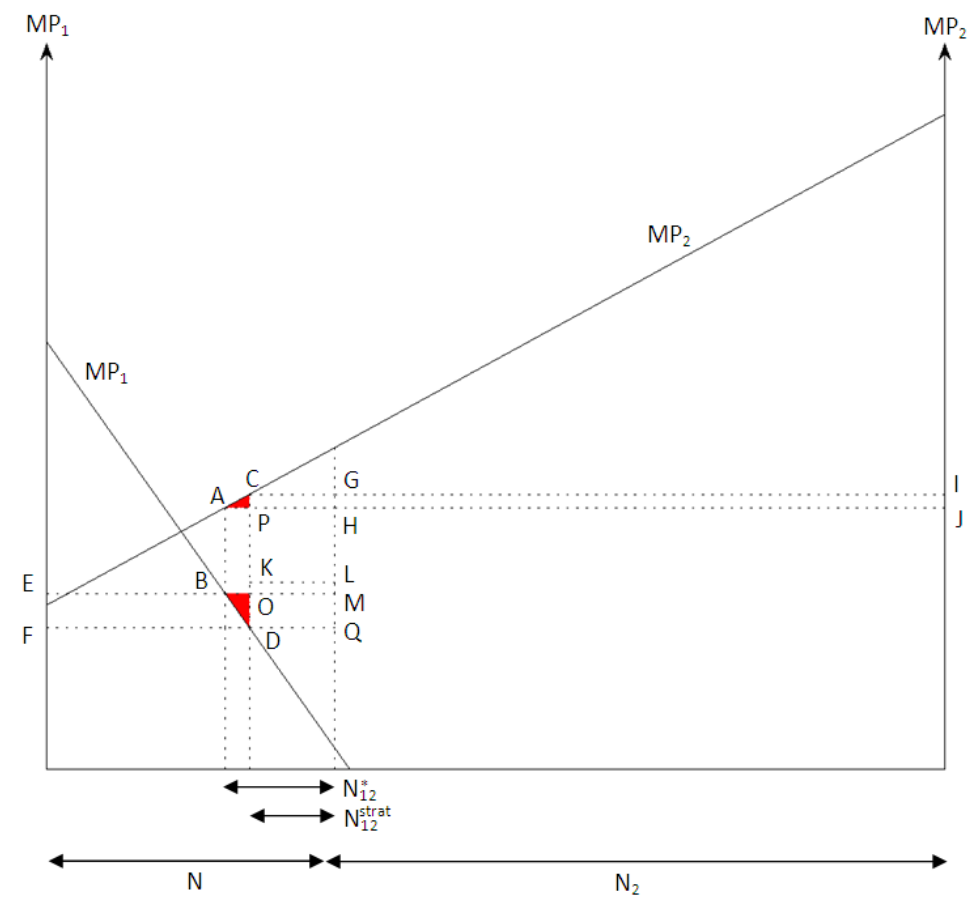

Figure 2: Welfare effects of a restricted number of commuters.

Region 1 will see an increase of local profits and wages of commuters. A lower number of commuters implies more people working in region 1, which will decrease local marginal products and wages. The impact on welfare in the city, region 2, is unambiguously negative. The loss in profits is larger than the income gain of city residents. Total welfare in the economy is decreased by the triangles $A C P$ and $B O D$.

\begin{tabular}{c|ccc}
\hline \hline & Region 1 & Region 2 & Total \\
& & & \\
Profits & + EBDF & -ACIJ & + EBDF - ACIJ \\
Real income & -EODF +KLMO & + GHIJ & -EODF + KLMO + GHIJ \\
Total & -BOD +KLMO & -ACGH & - ACP - BOD \\
\hline \hline
\end{tabular}

Table 2: Welfare effects of limiting the number of commuters

\subsection{Regional transport investment and commuting subsidy when labor is taxed}

We now derive optimal decisions of the regional government in wider framework. First we obtain analytical results in this setting. The next subsections discuss different effects 
separately. Assume there is a regional labor tax $t_{1}<1$. The government of region 1 then faces the following maximization problem:

$$
\begin{aligned}
& \underset{\operatorname{sax}_{1}, \psi_{1}}{\operatorname{Max}} W_{1}=\underbrace{\frac{1}{2} N_{1}\left(a_{1}-F_{1}^{\prime}\right)}_{\text {local profits }}+\underbrace{N_{1} F_{1}^{\prime}+N_{12}\left(F_{2}^{\prime}-c+\psi\right)}_{\text {local real income }}-\underbrace{K}_{\text {inv. cost }} \\
& \text { s.t. } \\
& N_{12}=\frac{1}{b_{1}+b_{2}}\left(a_{2}-a_{1}-\frac{1-s_{1}}{1-t_{1}}(c-\psi)+b_{1} N-b_{2} N_{2}\right)
\end{aligned}
$$

The regional government can now subsidize commuting at a rate of $s_{1}$. Setting the first order condition with respect to $s_{1}$ equal to 0 gives an expression for the regional commuting subsidies:

$$
s_{1}=-\frac{b_{2}}{(c-\psi)\left(b_{1}+2 b_{2}\right)}\left(a_{2}-a_{1}-c+\psi+N b_{1}-N_{2} b_{2}\right)\left(1-t_{1}\right)+t_{1}
$$

To make a clear case, the effects embodied by this expression will be analyzed step by step. First we ignore transport investments. Next, the additional interactions with preexisting labor market distortions are included when we replace lump sum taxation by a tax on labor. Finally, transport investments are added to the analysis.

\subsubsection{Lump sum taxation and only commuting subsidies}

If we assume lump sum taxation is possible (set $t_{1}=0$ in equation (18) to cancel out the labor tax distortion), we can isolate the strategic effect. The expression for the optimal commuting subsidy boils down to

$$
s_{1}^{s t r a t}=-\frac{b_{2}}{c b_{1}+2 c b_{2}}\left(a_{2}-a_{1}-c+N b_{1}-N_{2} b_{2}\right) .
$$

Under the assumptions made in section 3.1, $s_{1}^{\text {strat }}<0$ and the government taxes commuters instead of subsidizing. Therefore, the resulting number of commuters,

$$
N_{12}^{\text {strat }}=\frac{1}{b_{1}+\mathbf{2} b_{2}}\left(a_{2}-a_{1}-c+N b_{1}-N_{2} b_{2}\right)
$$

will be restricted by the regional government. We can compare with expression (7) (with $\psi=0)$ to see that this is indeed the case. Whereas an efficiency-preserving social planner would set commuting subsidies equal to 0, the regional government limits the number of commuters by levying a tax on commuting. This will cause an increase of wages of commuters. 


\subsubsection{Labor taxation and commuting subsidies}

We keep $\psi=0$, but consider the interaction with a regional labor tax $t_{1}$. This section shows that whether the regional government sets a commuting tax or a subsidy depends on two countervailing forces. Correcting the labor tax distortion asks for a subsidy, whereas strategic reasons provide an incentive for a commuting tax or an underinvestment in road or rail infrastructure, for instance. The trade-off can be shown more explicitly. In particular, the regional government taxes commuters if $s_{1}$ is negative, so if ${ }^{5}$

$$
\begin{gathered}
-\frac{b_{2}}{c b_{1}+2 c b_{2}}\left(a_{2}-a_{1}-c+N b_{1}-N_{2} b_{2}\right)\left(1-t_{1}\right)+t_{1}<0 \\
\Longleftrightarrow \\
|\underbrace{s_{1}^{\text {strat }} \mid}_{\text {Strategic effect }}>| \underbrace{\frac{t_{1}}{t_{1}-1} \mid}_{\text {Distortive effect }}
\end{gathered}
$$

The left-hand side captures the strategic effect. The right-hand side shows the distortion caused by the taxation of labor. With $t_{1}<1$, the commuting subsidy will not fully cover the commuting expenses $\left(s_{1}<t_{1}\right)$. Whereas efficiency concerns ask for a complete deductibility of commuting expenses, as discussed in section 3.2, strategic motives will prevent the regional government from setting $s_{1}=t_{1}$. Again, this reduces the number of commuters compared to the social planner outcome.

\subsubsection{Labor taxation, transport investments and commuting subsidies}

Now add transport investments as a second instrument of transport policy. We then obtain the full expression given by (18). The marginal benefit of investing in infrastructure depends on the number of commuters. Since the trade-off in previous subsection results in a restricted number of commuters, the marginal benefit of infrastructure investments will be reduced. Therefore, the level of these investments will be lower than socially optimal. Note that the optimal subsidy $s_{1}$ is decreasing in $\psi$. This means that a higher transport investment will bring about a higher tax on commuters. This makes sense: as transport costs are reduced, more people choose to commute. But to keep wages of commuters high, the commuting should be restricted. In short, the government invests to reduce the commuting costs and limits the commuting flow by setting a tax on commuting.

\footnotetext{
${ }^{5}$ See appendix B for more details.
} 


\section{$5 \quad$ Strategic behavior of city government}

The previous section supposed that region 1 was a dominant supplier of labor in the city. This section turns that assumption around and analyses the situation in which the city is a dominant player on the demand side of the labor market. In case of regional labor taxes, the commuting tax or subsidy is a neutral transfer in the eyes of the government of region 1 . In fact, the regional government has contradictory objectives when transportation investments are added as a policy instrument. Reducing transport costs, on the one hand, and thereby increasing the number of commuters, is beneficial because transport costs are a loss for its commuters. On the other hand, strategic arguments would restrict the number of commuters, for instance through lower investments in infrastructure or by pricing commuting. These two arguments influence the commuting flow in opposite directions.

For region 2, the city, the situation is different. In principle (under the assumptions made), the city would prefer as much commuting inflow as possible, since this causes an increase in local profits that overcompensates the local income losses (recall figure 2 and table 2). The idea to restrict the number of commuters thus has a different origin: taxing commuters gives an extra government income. This reasoning suggests that the city may have an incentive to invest strongly in transport infrastructure - in order to keep the number of commuters high - in combination with a high tax on commuters - to increase government revenue from tax exporting. We show that the city government may have an incentive for tax exporting and study the interaction between transport policy instruments.

\subsection{Transport investments and commuting taxes at city level}

Consider transport investments (denoted here by $\phi)$ and commuting taxes $s_{2}\left(s_{2}<0\right)$ at the city level. Assume the city has the following costs associated with investments in transport:

$$
K_{c}(\phi)=m \phi+\frac{1}{2} n \phi^{2}
$$

$m, n>0$. The city government then has an incentive to set high taxes on commuters and high investments in transport. The city government faces the objective function

$$
\underset{s_{2}, \phi}{\operatorname{Max}} W_{2}=\underbrace{\frac{1}{2}\left(N_{12}+N_{2}\right)\left(a_{2}-F_{2}^{\prime}\right)}_{\text {local profits }}+\underbrace{N_{2} F_{2}^{\prime}}_{\text {local real income }}-\underbrace{N_{12} c s_{2}}_{\text {tax revenue }}-\underbrace{K_{c}}_{\text {inv. cost }}
$$

However, a high investment reduces tax income per commuter, since we express the tax on the basis of the commuting cost: $\left(1-s_{2}\right)(c-\phi)$. Note that, in contrast with the objective 
function of region 1, the tax revenue is taken into account. The first order condition with respect to $s_{2}$ gives

$$
s_{2}=-\frac{1}{c-\phi} \frac{b_{1}-t\left(b_{1}+b_{2}\right)}{2 b_{1}+b_{2}-2 t\left(b_{1}+b_{2}\right)}\left(\left(a_{2}-a_{1}+N b_{1}-N_{2} b_{2}\right)(1-t)-c+\phi\right)
$$

We will set $t=0$ in the rest of this section to simplify the analysis. For now, remark two effects. First, note that this is indeed a tax $\left(s_{2}<0\right)$ for $\phi=0$. Second, the expression above shows that city will set a higher tax on commuters when the level of transport investments is higher. The first order condition with respect to $\phi$ gives

$$
\underbrace{\left(1-s_{2}\right)}_{(1)}(\underbrace{\frac{b_{2}}{b_{1}+b_{2}} N_{12}}_{(2)}-\underbrace{\frac{c s_{2}}{b_{1}+b_{2}}}_{(3)})=m+n \phi
$$

Marginal benefit of investing in infrastructure, on the left-hand side of expression (20), now depends on three factors. We discuss these in turn.

Term (1) shows that an investment in transport also lowers the tax per commuter, since this is $s_{2}(c-\phi)$. So if transport costs are reduced by one unit, the net benefit for commuters is only $\left(1-s_{2}\right)$ units. Therefore, the commuting subsidy reduces the impact of transport investments on commuting flow.

Term (2) is the marginal benefit of investing in transport infrastructure if the city does not have the possibility to tax or subsidize commuters, $s_{2}=0$. The reason for the city to invest in infrastructure is not to reduce transport costs (these are incurred by commuters), but just to increase commuting, which drives down local wages and raises the level of production and profits in the city. We see that the investments will be lower than socially optimal (assuming the same cost structure of investments, $k=m$ and $l=n$ ), but it makes more sense to stress the difference in incentives. Comparing with (15) shows that the marginal benefit for the federation equals the sum of marginal benefits of the region and the city.

Term (3) enters the first order condition because a higher level of investments causes more workers to commute, thereby also increasing the tax revenues. Therefore, this term represents the tax exporting behavior. It depends on the size of the subsidy (numerator) and how the number of commuters is affected by an investment in transport (denominator, together with term (1)). Note that $s_{2}<0$, such that the tax revenues are included as an additional marginal benefit of infrastructure investment. 


\section{Nash competition in transport investments}

This section looks into Nash competition between the regional and the city government when both can invest in transport infrastructure. We ignore commuting subsidies or taxes and assume lump sum taxation is possible. The number of commuters is then given by

$$
N_{12}=\frac{1}{b_{1}+b_{2}}\left(a_{2}-a_{1}-c+\psi+\phi+N b_{1}-N_{2} b_{2}\right)
$$

From expressions (15) and (20) (with $s_{2}=0$ ) we get the optimal investment rules:

$$
\begin{aligned}
& \frac{b_{1}}{b_{1}+b_{2}} N_{12}=k+l \psi \\
& \frac{b_{2}}{b_{1}+b_{2}} N_{12}=m+n \phi
\end{aligned}
$$

Both these reaction curves are increasing in the level of infrastructure investment from the other region. The intuition is the following. When the city invests more in transport infrastructure, more workers will commute. More commuters implies more individuals who benefit from a reduction in transport costs. Therefore the marginal benefit of investment will be higher for region 1 . To compare the total level of investments with the social planner outcome of section 3.1, we assume that both the region as the city have the same costs of investing in transport. Solving for $\psi$ and $\phi$, with $k=m$ and $l=n$, and summing to obtain the total level of investments, we get ${ }^{6}$

$$
\psi+\phi=\frac{1}{l\left(b_{1}+b_{2}\right)-1}\left(a_{2}-a_{1}-c+N b_{1}-N_{2} b_{2}-\mathbf{2} k\left(b_{1}+b_{2}\right)\right)
$$

The total investment in transport is lower than in the social planner case. This can be seen by comparing with expression (10). In conclusion, the outcome of the Nash competition in transport investments results in a level of investments that is too low from a social point of view.

\footnotetext{
${ }^{6}$ See appendix $\mathrm{C}$.
} 


\section{$7 \quad$ Alternative scenarios}

In this section, we relax or alter some of the assumptions. First, we include a third region. Next, we discuss the impact of revenue sharing of federal taxes. The final assumption we change is that profits are captured locally.

\subsection{Three regions}

This section discusses the effects of Cournot competition among governments on the labor market in the city or region 2 . Consider a third region with $M$ inhabitants. The number of individuals that live and work in this region is denoted $N_{3}$. Productivity and wages in this region are lower than in region 2 , so workers have an incentive to commute to this region. $N_{32}$ workers will do so. If region 3 is also a dominant supplier of labor in region 2, its government will have an incentive to set a tax on commuting, as discussed for region 1. Assume lump sum taxation and no investments in transport. The inclusion of a third region, that also supplies labor to the city, reduces regional strategic behavior ${ }^{7}$ :

$$
s_{1}^{\text {Cournot }}=\underbrace{-\frac{b_{2}}{\left(c b_{1}+2 c b_{2}\right)}\left(a_{2}-a_{1}-c+N b_{1}-N_{2} b_{2}\right)}_{s_{1}^{\text {strat }}} \underbrace{\frac{\left(b_{1}^{2}+3 b_{1} b_{2}+b_{2}^{2}\right)}{\left(b_{1}^{2}+4 b_{1} b_{2}+3 b_{2}^{2}\right)}}_{<1}
$$

Because region 1 is no longer the only supplier of labor in the city, its position is now less dominant. If the government of region 1 decides to reduce the number of commuters to keep wages in the city high, then an increased commuting flow from region 2 will (partially) offset the desired effect. Therefore, region 1 has a weaker incentive to set commuting taxes.

\subsection{Revenue sharing mechanisms}

Assume there is a federal labor tax and consider a framework with only two regions. Define $\theta_{1}$ as the share of federal tax revenue that goes to region $1\left(0<\theta_{1}<1\right)$. Consider the case where the lower level government decides on the commuting tax and the investments in transport infrastructure. The regional government now maximizes the following objective function:

$$
\begin{aligned}
\underset{N_{12}, \psi}{\operatorname{Max}} W_{1}= & \frac{1}{2} N_{1}\left(a_{1}-F_{1}^{\prime}\right)+N_{1} F_{1}^{\prime}+N_{12}\left(F_{2}^{\prime}-(c-\psi)\right)-K \\
& +\theta_{1} t\left(N_{1} F_{1}^{\prime}+\left(N_{12}+N_{2}\right) F_{2}^{\prime}\right) \\
& -t\left(N_{1} F_{1}^{\prime}+N_{12} F_{2}^{\prime}\right)
\end{aligned}
$$

\footnotetext{
${ }^{7}$ The derivation can be found in appendix D.
} 
where the last two lines represent region 1's share of federal tax revenues and its taxes paid, respectively. These no longer cancel each other out as is the case with a regional labor (or lump sum) tax. Rewriting the problem brings out the necessary intuition to analyze the problem:

$$
\underset{N_{12}, \psi}{\operatorname{Max}} W_{1}=\underbrace{\frac{1}{2} N_{1}\left(a_{1}-F_{1}^{\prime}\right)}_{(1)}+\underbrace{\left(1-t+\theta_{1} t\right)\left(N_{1} F_{1}^{\prime}+N_{12} F_{2}^{\prime}\right)}_{(2)}+\underbrace{\theta_{1} t N_{2} F_{2}^{\prime}-N_{12}(c-\psi)-K}_{(3)}
$$

An analysis of this objective function is enough to understand the nature of the outcome. We distinguish four terms.

(1): Regional profits enter the objective function as before;

(2): A lower weight is given to real income of residents of region 1 , since $1-t+\theta_{1} t<1$;

(3): Income of residents of region 2 enters the objective function with a weight of $\theta_{1} t>0$;

(4): Commuting and investment cost are subtracted, as before.

Because higher income in region 2 increases the value of tax revenue redistributed to region 1, this region will now attach a weight to income in region 2. Furthermore, a lower weight is attached to income of its own residents. We might therefore be inclined to say that this situation will drive the outcome towards the social optimum. However, consider the welfare effects displayed in table 2 . The impact of restricting the number of commuters on real income of region 1 is given by area $-E O D F+K L M O$. This area is now given a lower weight. Note that this effect might be negative. A higher weight is now given to the income effect in region 2, which is positive $(+G H I J)$. Therefore, the sharing rule for the federal labor tax revenues might even intensify the strategic behavior of region 1.

One could also distinguish here between distribution of federal tax revenues according to place-of-residence and place-of-work. If the collected labor taxes are redistributed on the basis of the number of residents in a region, we get (for region 1)

$$
\theta_{1}=\frac{N_{1} F_{1}+N_{12} F_{2}}{N_{1} F_{1}+\left(N_{12}+N_{2}\right) F_{2}}
$$

In this case, tax revenue obtained from residents of region 1 is completely redistributed to that region. The last two lines of (21) would cancel each other out. However, if federal labor tax revenues are allocated to the regions in relation to the number of people that are 
employed in that region, i.e. on a place-of-work basis, the share $\theta_{1}$ becomes

$$
\theta_{1}=\frac{N_{1} F_{1}}{N_{1} F_{1}+\left(N_{12}+N_{2}\right) F_{2}}
$$

So region 1 would no longer receive funds from labor taxes levied on commuters, which boils down to a decrease of $\theta_{1}$. Following the same line of reasoning as in the previous paragraph, we conclude that labor tax redistribution according to the place-of-work principle might attenuate the strategic incentives of region 1 as compared to the situation of tax revenue sharing on the basis of place-of-residence.

\subsection{Ownership structure or profit taxes}

A similar reasoning can be made for different ownership structures. Until now, firm ownership was assumed to be local, i.e. local firms were owned by local residents. This section assumes that profit shares are spread across jurisdictional borders. The assumption that each individual owns only a negligible share of profits can still be made. Residents of region 1 now get a part of the profit made in region 2, and vice versa. Denote by $\delta_{1}$ the share of profits of firms in region 1 owned by residents of region $1\left(0<\delta_{1}<1\right)$. Similarly, let $\gamma_{1}$ be the profit share of region 1 inhabitants in profits of firms in region $2\left(0<\gamma_{1}<1\right)$. The objective function of the government of region 1 becomes:

$$
\underset{N_{12}, \psi}{\operatorname{Max}} W_{1}=N_{1} F_{1}^{\prime}+N_{12}\left(F_{2}^{\prime}-(c-\psi)\right)-K+\underbrace{\delta_{1} \frac{1}{2} N_{1}\left(a_{1}-F_{1}^{\prime}\right)}_{\text {share in profits region } 1}+\underbrace{\gamma_{1} \frac{1}{2}\left(N_{2}+N_{12}\right)\left(a_{2}-F_{2}^{\prime}\right)}_{\text {share in profits region } 2}
$$

An analysis of expression (25) reveals that local profits get a lower weight in the regional welfare function $\left(\delta_{1}<1\right)$ and profits made in the city now enter the objective function with a positive weight $\left(\gamma_{1}>0\right)$. Restricting the number of commuters affects profits in region 1 positively and profits in region 2 negatively (see table 2). A clear conclusion can be drawn: since a local government now cares less about profits on its own territory and more about profits made in the other region, the outcome will be closer to the social optimum. 


\section{Numerical example for Belgium}

In this section, the model is calibrated such that the outcome reflects a realistic situation. We use Belgium as an example. Brussels serves as a large employment center, attracting many workers from the regions of Flanders and Wallonia, North and South of Brussels respectively. To illustrate some of the effects discussed in the analytical part of the paper, we restrict the example to include only the capital of Brussels and the region of Flanders. Proost and Sen (2006) adopt a transport model to estimate the potential welfare losses when pricing instruments are controlled by different levels of government. Their application on Brussels yields only limited overall efficiency losses compared to the situation where there is only one government level.

Several hypothetical situations will be analyzed for the simple model with two regions and without transport investments. First, the social planner outcome will be calculated and will serve as a benchmark for comparison. Efficiency measures will compare welfare levels with this social planner result. Next, we discuss a situation where Flanders limits the number of commuters ${ }^{8}$. Subsequently, Brussels acts as a strategic player on the demand side of the labor market and sets a commuting tax.

To stay in line with the notation used before and with the realistic picture in Belgium, we denote Flanders as region 1 and Brussels as region 2. Residents of Flanders can commute to Brussels $\left(N_{12}\right)$ or work in the region of Flanders $\left(N_{1}\right)$. In the model equilibrium, net wages of all Flemish people are equalized, but there is a gap between wages in Flanders and wages in Brussels. This gap is indeed what is observed in reality: the average gross wage disparity was about $17 \%$ in 2007 . Note that this is partially due to differences in skill composition of the labor force. The data presented in table 3 will be used for the calibration.

Table 3: Data used for calibration

\begin{tabular}{c|c}
\hline \hline & \\
Average Gross monthly wage in Flanders & $2796 €$ \\
Average Gross monthly wage in Brussels & $3263 €$ \\
Paid Workers $N_{1}{ }^{*}$ & 1942 \\
Commuters $N_{12}{ }^{*}$ & 239 \\
Paid Workers $N_{2}{ }^{*}$ & 217 \\
\hline \hline
\end{tabular}

* Number of people in thousands.

\footnotetext{
${ }^{8}$ Either directly or via commuting taxes, which was shown to be equivalent.
} 
The data on gross average regional wages, provided by Statistics Belgium ${ }^{9}$, is dated October 2007. These wages concern full-time workers only. Numbers of workers in each region and number of commuters are based on estimates for the year 2007 of the Department of Work and Social Economics Flanders ${ }^{10}$. Reports of the Flemish Government ${ }^{11}$ provide a discussion of the data on commuting available in the Census Data (2001). The numbers used are those for paid workers (excluding self-employed workers). We define the commuting cost as the difference between gross wages in both regions.

Let us turn to the calibration procedure. We need values for the parameters of the production functions $\left(a_{1}, b_{1}, a_{2}, b_{2}\right)$, for the number of individuals of each type $\left(N_{1}, N_{12}\right.$, $N_{2}$ ) and for the commuting cost $c$. With the data presented in table 3 and the assumption of linearly decreasing marginal products, we only need the slopes $b_{1}$ and $b_{2}$ to calibrate the model. We derive these for a range of labor demand elasticities. Assuming a competitive labor market, workers are paid their marginal product. Denoting by $w_{1}$ and $w_{2}$ the gross wages in Flanders and Brussels respectively, we get:

$$
\begin{aligned}
& w_{1}=F_{1}^{\prime}=a_{1}-b_{1} N_{1} \\
& w_{2}=F_{2}^{\prime}=a_{2}-b_{2}\left(N_{12}+N_{2}\right)
\end{aligned}
$$

Note that gross average wages are used in the calibration. Using gross wages means we implicitly assume that the labor tax revenue is redistributed to the regions. The use of average wages means we neglect the differences in skill composition of the labor force in the two regions. Taking these into account might reduce the wage gap. From these expressions we can write the number of workers in a region as a function of the wage, expressing labor demand. For instance, for region 1 we obtain the labor demand $L D_{1}=-\frac{w_{1}-a_{1}}{b_{1}}$, with partial derivative $\frac{\partial L D_{1}}{\partial w_{1}}=-\frac{1}{b_{1}}$. This means labor demand elasticity can be stated as $\varepsilon_{1}^{L D}=\frac{\partial L D_{1}}{\partial w_{1}} \frac{w_{1}}{N_{1}}=$ $-\frac{1}{b_{1}} \frac{w_{1}}{N_{1}}$. For different values of labor demand elasticity, we then obtain different values for $b_{1}=-\frac{1}{\varepsilon_{1}^{L D}} \frac{w_{1}}{N_{1}}$. We let this elasticity vary from -0.2 to -0.8 . Similar calculations are done to obtain values for $b_{2}$. In the results presented here, we assume labor demand elasticities are the same in Brussels and in Flanders, so we can write $\varepsilon^{L D}$. Letting the absolute value of labor demand elasticity in one region rise relative to the other region will slightly change the results in the benefit of the former region. Tables 4 and 5 show welfare changes $(\Delta)$ in Brussels and Flanders in the different scenarios. The last column (Efficiency) compares with the social optimum.

\footnotetext{
${ }^{9} \mathrm{http} / /$ /statbel.fgov.be/nl/statistieken/cijfers/arbeid_leven/lonen/maandloon/index.jsp

${ }^{10}$ Steunpunt WSE, http://www.werk.be/ (Vlaamse arbeidsrekening)

${ }^{11} \mathrm{http}$ // /economie.fgov.be (Monografie pendel)
} 
Table 4: Flanders sets number of commuters*

\begin{tabular}{c|ccc}
\hline \hline$\varepsilon^{L D}$ & $\% \Delta$ welfare Flanders & $\% \Delta$ Welfare Brussels & Efficiency $(\%)$ \\
\hline$-0,2$ & $+2,36$ & $-16,21$ & 98,95 \\
$-0,4$ & $+1,80$ & $-13,97$ & 99,18 \\
$-0,5$ & $+1,61$ & $-13,07$ & 99,26 \\
$-0,6$ & $+1,46$ & $-12,28$ & 99,33 \\
$-0,8$ & $+1,22$ & $-10,95$ & 99,43 \\
\hline \hline
\end{tabular}

* Number of commuters $=130423$.

Table 4 presents the situation where Flanders behaves strategically by restricting the number of commuters. This number drops from 239000 to 130423 . When labor demand is rather inelastic, $\varepsilon^{L D}=-0.2$, Flanders can increase the welfare of its residents with $2.36 \%$. Brussels would then face a significant welfare decrease of $16.21 \%$. The overall welfare level is only slightly reduced to about $99 \%$ of the efficient level. For more elastic labor demands, the effects become smaller. The overall efficiency loss is smaller than $0.6 \%$ for $\varepsilon^{L D}=-0.8$.

Table 5: Brussels sets commuting tax*

\begin{tabular}{c|ccc}
\hline \hline$\varepsilon^{L D}$ & $\% \Delta$ welfare Flanders & $\% \Delta$ Welfare Brussels & Efficiency $(\%)$ \\
\hline$-0,2$ & $-0,28$ & $+0,67$ & 99,90 \\
$-0,4$ & $-0,21$ & $+0,57$ & 99,92 \\
$-0,5$ & $-0,19$ & $+0,54$ & 99,93 \\
$-0,6$ & $-0,17$ & $+0,50$ & 99,93 \\
$-0,8$ & $-0,14$ & $+0,45$ & 99,94 \\
\hline \hline
\end{tabular}

${ }^{*}$ Number of commuters $=204711$.

The situation were Brussels taxes commuters is shown in table 5. A small welfare increase for Brussels goes at the cost of a decreasing welfare level in Flanders. Overall welfare losses seem to be rather unimportant.

It is important to remark that the numerical example is presented for illustrative purposes. It shows the effects derived theoretically and gives an idea on the size of these effects. Note that the commuting taxes were not restricted here to values between -1 and 1 (i.e. a fraction of commuting costs). On the contrary, the highest tax in this example was about ten times the commuting cost (in the case where $\varepsilon^{L D}=-0.2$ and Flanders is the only region to set a $\operatorname{tax})$. 


\section{Conclusions}

The main contribution of this paper is the introduction of a strategic aspect in commuting policy in a federation with a limited number of regions. Whereas traditional arguments for road pricing rest upon externalities, e.g. congestion or pollution, this paper presents strategic arguments in regional government competition as a motive for a level of infrastructure investments that is suboptimal from the federal point of view.

In the framework presented in this paper, a region that 'exports labor' behaves strategically by restricting the number of people that work in the other region, either by taxing commuters or by investing less in infrastructure. If less people commute because of a commuting tax, the marginal benefit of investing in transport infrastructure will be lower. Therefore, taxing commuters also results in lower transport investments. The urban area or city that attracts commuters might also benefit from taxing commuters. The relevant trade-off, in this case, is between tax revenue and profit losses.

However, there might be influences that attenuate the strategic effect. Three factors are considered. Firstly, a third region can be introduced. When this region also supplies labor to the same city or central business district, the market power of the dominant labor supplier diminishes. This will result in a lower commuting tax and a higher investment level of the region that was previously the dominant supplier of labor. Secondly, an exogenous sharing rule for the redistribution of federal labor tax proceeds introduces interdependencies between regions' government revenues. Finally, when firm ownership is spread across the federation, the incentive for restricting the number of commuters is reduced.

The authors wish to stress that this version of the paper is work in progress. In the near future, we hope to analyze how the federal government can correct incentive structures through mechanism design. Furthermore, we would like to explore vertical tax competition in this framework. Also, future research could include agglomeration or congestion externalities. 


\section{References}

Arnott, R. (2007): "Congestion tolling with agglomeration externalities," Journal of Urban Economics, 62(2), 187 - 203, Essays in Honor of Kenneth A. Small.

Borck, R., And M. Wrede (2008): "Commuting subsidies with two transport modes," Journal of urban economics, 63(3), 841-848.

Borck, R., And M. Wrede (2009): "Subsidies for intracity and intercity commuting," Journal of Urban Economics, 66(1), 25 - 32.

Brueckner, J. K. (2005): "Transport subsidies, system choice, and urban sprawl," Regional Science and Urban Economics, 35(6), 715 - 733.

De Borger, B., F. Dunkerley, and S. Proost (2007): "Strategic investment and pricing decisions in a congested transport corridor," Journal of Urban Economics, 62(2), 294 - 316, Essays in Honor of Kenneth A. Small.

De Borger, B., and S. Proost (2004): "Vertical and horizontal tax competition in the transport sector," Reflets et perspectives de la vie économique, 0(4), 45-64.

De Borger, B., S. Proost, and K. V. Dender (2005): "Congestion and tax competition in a parallel network," European Economic Review, 49(8), 2013 - 2040.

Graham, D. J., And K. V. Dender (2008): "Pricing Congestion with Heterogeneous Agglomeration Externalities and Workers," Working paper.

Gutiérrez-i Puigarnau, E., and J. N. van Ommeren (2010): "Labour supply and commuting," Journal of Urban Economics, 68(1), 82 - 89.

Marshall, A. (1920): Principles of Economics: An Introductory Volume. McMillen, London, UK.

Mirrlees, J. (1972): "The Optimum Town.," Swedish Journal of Economics, 74(1), 114.

OAtes, W. E. (1999): "An Easy on Fiscal Federalism.," Journal of Economic Literature, $37(3), 1120$.

Parry, I. W., And A. Bento (2001): "Revenue Recycling and the Welfare Effects of Road Pricing.," Scandinavian Journal of Economics, 103(4), 645. 
Proost, S., And A. Sen (2006): "Urban transport pricing reform with two levels of government: A case study of Brussels," Transport Policy, 13(2), 127 - 139, Modelling of Urban Road Pricing and its Implementation.

Rosenthal, S., and W. Strange (2004): Handbook of Urban and Regional Economicsvol. 4, chap. Evidence on the nature and source of agglomeration economies. Elsevier, Amsterdam.

Stutzer, A., And B. Frey (2008): "Stress that Doesn't Pay: The Commuting Paradox," The Scandinavian journal of economics, 110(2), 339-366.

Ubbels, B., and E. Verhoef (2008): "Governmental competition in road charging and capacity choice," Regional science and urban economics, 38(2), 174-190.

Van Ommeren, J., and P. Rietveld (2007): "Compensation for commuting in imperfect urban markets.," Papers in Regional Science, 86(2), 241 - 259.

Venables, A. J. (2007): "Evaluating Urban Transport Improvements: CostBenefit Analysis in the Presence of Agglomeration and Income Taxation," Journal of transport economics and policy, 41(2), 173-188.

Verhoef, E. T., and P. NiJkamp (2003): "Externalities in the Urban Economy," SSRN eLibrary.

Wrede, M. (2001): "Should Commuting Expenses Be Tax Deductible? A Welfare Analysis," Journal of Urban Economics, 49(1), 80 - 99. (2009): "A Distortive Wage Tax and a Countervailing Commuting Subsidy," Journal of Public Economic Theory, 11(2), 297-310. 


\section{Appendix}

\section{A Regional transport investments}

From the optimal investment rule

$$
N_{12}\left(\frac{b_{1}}{b_{1}+b_{2}}\right)=k+l \psi
$$

we can get an expression for the investment level

$$
\psi=\frac{1}{l\left(b_{1}+b_{2}\right)-\frac{b_{1}}{b_{1}+b_{2}}}\left(\frac{b_{1}}{b_{1}+b_{2}}\left(a_{2}-a_{1}-c+N b_{1}-N_{2} b_{2}\right)-k\left(b_{1}+b_{2}\right)\right),
$$

which is smaller than the investment level $\psi^{*}$, expressed by equation (10). The resulting number of commuters is lower than optimal:

$$
N_{12}=\frac{l}{l\left(b_{1}+b_{2}\right)-\frac{b_{1}}{b_{1}+b_{2}}}\left(a_{2}-a_{1}-c+N b_{1}-N_{2} b_{2}-\frac{k}{l}\right)
$$

\section{B Trade-off}

$$
\begin{aligned}
s_{1} & =-\frac{b_{2}}{c b_{1}+2 c b_{2}}\left(a_{2}-a_{1}-c+N b_{1}-N_{2} b_{2}\right)\left(1-t_{1}\right)+t_{1} \\
& =\left(1-t_{1}\right) s_{1}^{\text {strat }}+t_{1}=s_{1}^{\text {strat }}+t_{1}\left(1-s_{1}^{\text {strat }}\right),
\end{aligned}
$$

where $s_{1}^{\text {strat }}$ is given by expression (19). Given that $s_{1}^{\text {strat }}<0, s_{1}$ is now less negative than

$s_{1}^{\text {strat }}$. Another relevant comparison can be made, namely with the social planner outcome of section 3.1. There the outcome was $s=t$. Region 1 now behaves strategically and sets a lower subsidy than the labor tax rate:

$$
\begin{aligned}
& s_{1}^{\text {strat }}+t_{1}\left(1-s_{1}^{\text {strat }}\right)<t_{1} \\
& \Longleftrightarrow s_{1}^{\text {strat }}<t_{1} s_{1}^{\text {strat }} \\
& \Longleftrightarrow t_{1}<1,
\end{aligned}
$$

which is the case under the assumptions made (labor cannot be taxed at more than $100 \%$ ). So we know the regional government sets the commuting tax lower than in the case with lump sum taxes, and provides a lower commuting subsidy than in the federal social 
planner parallel. This situation can result in a lower tax or even a subsidy. The following proposition sheds some light on this issue:

Proposition 1 In a setting with a regional labor tax and commuting policy (commuting tax or subsidy; no transport investments), the regional government provides a commuting subsidy if and only if $s_{1}^{\text {strat }}>\frac{t_{1}}{t_{1}-1}$.

Proof. Region 1 installs a subsidy if:

$$
\begin{aligned}
s_{1} & >0 \\
& \Longleftrightarrow s_{1}^{\text {strat }}+t_{1}\left(1-s_{1}^{\text {strat }}\right)>0 \\
& \Longleftrightarrow 1-s_{1}^{\text {strat }}>-\frac{s_{1}^{\text {strat }}}{t_{1}} \\
& \Longleftrightarrow t_{1}>\left(t_{1}-1\right) s_{1}^{\text {strat }} \\
& \Longleftrightarrow s_{1}^{\text {strat }}>\frac{t_{1}}{t_{1}-1}
\end{aligned}
$$

\section{Nash competition in investments}

The spatial equilibrium condition is now given by

$$
N_{12}=\frac{1}{b_{1}+b_{2}}\left(a_{2}-a_{1}-c+\psi+\phi+N b_{1}-N_{2} b_{2}\right)
$$

The reaction functions:

$$
\begin{aligned}
& \frac{b_{1}}{b_{1}+b_{2}} N_{12}=k+l \psi \\
& \psi=\frac{b_{1}}{l b_{1}^{2}+2 l b_{1} b_{2}-b_{1}+l b_{2}^{2}}\left(a_{2}-a_{1}-c+\phi+N b_{1}-N_{2} b_{2}-\frac{k}{b_{1}}\left(b_{1}+b_{2}\right)^{2}\right) \\
& \psi=\frac{b_{1}}{l\left(b_{1}+b_{2}\right)^{2}-b_{1}}\left(a_{2}-a_{1}-c+\phi+N b_{1}-N_{2} b_{2}\right)-\frac{k\left(b_{1}+b_{2}\right)^{2}}{l\left(b_{1}+b_{2}\right)^{2}-b_{1}} \\
& \frac{b_{2}}{b_{1}+b_{2}} N_{12}=m+n \phi \\
& \phi=\frac{b_{2}}{n\left(b_{1}+b_{2}\right)^{2}-b_{2}}\left(a_{2}-a_{1}-c+\psi+N b_{1}-N_{2} b_{2}-\frac{m}{b_{2}}\left(b_{1}+b_{2}\right)^{2}\right) \\
& \quad \phi=\frac{b_{2}}{n\left(b_{1}+b_{2}\right)^{2}-b_{2}}\left(a_{2}-a_{1}-c+\psi+N b_{1}-N_{2} b_{2}\right)-\frac{m\left(b_{1}+b_{2}\right)^{2}}{n\left(b_{1}+b_{2}\right)^{2}-b_{2}}
\end{aligned}
$$

Now impose $m=k$ and $n=l$. Solving then gives: 


$$
\begin{aligned}
& \phi=\frac{1}{\left(b_{1}+b_{2}\right)-l\left(b_{1}+b_{2}\right)^{2}}\left(-b_{1} \frac{k}{l}+b_{2} \frac{k}{l}+N_{2} b_{2}^{2}+c b_{2}+a_{1} b_{2}-a_{2} b_{2}+k b_{1}^{2}+k b_{2}^{2}-N b_{1} b_{2}+2 k b_{1} b_{2}\right) \\
& \psi=\frac{1}{\left(b_{1}+b_{2}\right)-l\left(b_{1}+b_{2}\right)^{2}}\left(b_{1} \frac{k}{l}-b_{2} \frac{k}{l}+c b_{1}+a_{1} b_{1}-a_{2} b_{1}-N b_{1}^{2}+k b_{1}^{2}+k b_{2}^{2}+2 k b_{1} b_{2}+N_{2} b_{1} b_{2}\right) \\
& \psi+\phi=\frac{1}{l\left(b_{1}+b_{2}\right)-1}\left(a_{2}-a_{1}-c+N b_{1}-N_{2} b_{2}-2 k\left(b_{1}+b_{2}\right)\right)
\end{aligned}
$$

\section{Three regions}

$$
\begin{aligned}
& N_{12}=\frac{1}{b_{1}+b_{2}}\left(a_{2}-a_{1}-c\left(1-s_{1}\right)+N b_{1}-b_{2}\left(N_{2}+N_{32}\right)\right) \\
& N_{32}=\frac{1}{b_{2}+b_{3}}\left(a_{2}-a_{3}-c\left(1-s_{3}\right)+N b_{3}-b_{2}\left(N_{2}+N_{12}\right)\right)
\end{aligned}
$$

The steps taken to get an expression for the optimal commuting tax are as follows. Firstly, expression (31) and (32) are substituted in $W_{1}$. The government of region 1 then optimizes with $s_{1}$ as choice variable, taking $N_{32}$ as given. The outcome is the optimal commuting tax $s_{1}$ as a function of $N_{32}$. Next, replacing this tax in the expression above results in the reaction function (33) (and (34) for region 3). Now impose symmetry, i.e. region 1 and 3 are identical. Finally, substituting the solution $N_{32}^{\text {Cournot }}$ in the expression for $s_{1}$, the Cournot outcome for the commuting tax is obtained.

The numbers of commuters are now given by

$$
\begin{aligned}
& N_{12}=\frac{1}{b_{1}+b_{2}}\left(a_{2}-a_{1}+N b_{1}-b_{2}\left(N_{2}+N_{32}\right)-c\left(1-s_{1}\right)\right) \\
& N_{32}=\frac{1}{b_{2}+b_{3}}\left(a_{2}-a_{3}+N b_{3}-b_{2}\left(N_{2}+N_{12}\right)-c\left(1-s_{3}\right)\right)
\end{aligned}
$$

Welfare in region 1 is given by

$W_{1}=\frac{1}{2} N_{1}\left(a_{1}-\left(a_{1}-b_{1}\left(N-N_{12}\right)\right)\right)+N_{1}\left(a_{1}-b_{1}\left(N-N_{12}\right)\right)+N_{12}\left(a_{2}-b_{2}\left(N_{2}+N_{12}+N_{32}\right)-c\right)$

First order condition:

$$
\frac{\partial}{\partial s_{1}} W_{1}=\frac{c}{\left(b_{1}+b_{2}\right)^{2}}\left(N_{2} b_{2}^{2}+b_{2}^{2} N_{32}+c b_{2}+a_{1} b_{2}-a_{2} b_{2}-N b_{1} b_{2}-c b_{1} s_{1}-2 c b_{2} s_{1}\right)=0
$$

From this we obtain optimal taxes as functions of the number of commuters of the other 
region:

$$
\begin{aligned}
& s_{1}=\frac{b_{2}}{c b_{1}+2 c b_{2}}\left(c+a_{1}-a_{2}-N b_{1}+N_{2} b_{2}+b_{2} N_{32}\right) \\
& s_{3}=\frac{b_{2}}{c b_{3}+2 c b_{2}}\left(c+a_{3}-a_{2}-N b_{3}+N_{2} b_{2}+b_{2} N_{12}\right)
\end{aligned}
$$

Solving and imposing symmetry gives

$$
\begin{aligned}
s_{1}^{\text {Cournot }} & =-\frac{b_{2}}{\left(c b_{1}+2 c b_{2}\right)\left(b_{1}^{2}+4 b_{1} b_{2}+3 b_{2}^{2}\right)}\left(b_{1}^{2}+3 b_{1} b_{2}+b_{2}^{2}\right)\left(a_{2}-a_{1}-c+N b_{1}-N_{2} b_{2}\right) \\
N_{12}^{\text {Cournot }} & =\underbrace{\frac{\left(b_{1}+2 b_{2}\right)^{2}}{\left(b_{1}+2 b_{2}\right)^{2}-b_{2}^{2}}} \underbrace{\left(\frac{1}{b_{1}+2 b_{2}}\left(a_{2}-a_{1}-c+N b_{1}-N_{2} b_{2}\right)\right.}
\end{aligned}
$$


Copyright (c) 2011 @ the author(s). Discussion papers are in draft form. This discussion paper is distributed for purposes of comment and discussion only. It may not be reproduced without permission of the copyright holder. Copies of working papers are available from the author. 